\title{
La inacción de Estados Unidos en la Antártica durante la era heroica. Una mirada desde las sociedades científicas norteamericanas ${ }^{1}$
}

The US inaction in Antarctica during the heroic age.

A view from the American scientific societies

\author{
NeLSON LLANOS SierRa* \\ "Profesor Historia y Geografía, Mg. Relaciones Internacionales \\ Universidad de Playa Ancha, Valparaíso \\ $\measuredangle$ nelsonllanos@gmail.com
}

\begin{abstract}
RESUMEN ${ }^{1}$
Las exploraciones internacionales llevadas a cabo durante la denominada era heroica de la historia antártica, fueron determinantes en la configuración del futuro político del continente helado. Pese a ello, y mientras el Reino Unido, Francia, Bélgica, Noruega y otras naciones realizaban importantes y continuos esfuerzos para asegurar su presencia en dicha región, Estados Unidos -por entonces, una potencia en ascenso- permanecía al margen del proceso. De acuerdo a lo anterior, el presente trabajo intenta dilucidar algunas de las razones del comportamiento del país del norte, y -particularmente- examina las perspectivas que algunas influyentes sociedades científicas norteamericanas desarrollaron respecto de la inacción norteamericana en materia antártica durante la primera década del siglo XX. El trabajo -de carácter exploratorio- se basa, principalmente, en material de prensa, documentación institucional, y en artículos publicados en las revistas y boletines de las sociedades científicas analizadas.
\end{abstract}

PALABRAS CLAVE: Antártica, era heroica, sociedades científicas, Estados Unidos.

\section{ABSTRACT}

International expeditions during the so-called Antarctic heroic age were key for the political future of the white continent. Nevertheless, while the United Kingdom, France, Belgium, Norway and other nations carried out significant efforts to strengthen their

1 Proyecto FONDECYT 1170314. El Piloto $2^{\circ}$ Luis Pardo Villalón y la Segunda Carta Patente Británica: la Política Antártica Chilena entre la Pertenencia Histórica y la Incertidumbre Internacional, 1906-1917 
presence in the region, the United States -by then an emerging power- did not participate in the process. According to the above, this paper aspires to identify some of the reasons for the US Antarctic behavior, and -especially- it examines the perspectives that some of the most influential American scientific societies adopted toward the US Antarctic inaction during the first decade of the $20^{\text {th }}$ century. This exploratory work is mostly based on press materials, official documents, and articles appeared in journals and bulletins belonging to the scientific societies under analysis.

KEY WORDS: Antarctica, heroic age, scientific societies, United States.

\section{INTRODUCCIÓN}

Al iniciarse el siglo $\mathrm{XX}$, las fracturas y tensiones entre las tradicionales potencias europeas parecían advertir el pronto colapso del sistema imperialista y el fin del predominio del viejo continente sobre la política mundial. La guerras anglo-bóers en Sudáfrica; la derrota de Rusia a manos de Japón; la carrera armamentista; y el auge de los nacionalismos al interior de los viejos imperios -entre otros factores- resultaban ser claros síntomas de lo descrito. Aunque la totalidad de África, así como gran parte del océano Pacífico, Asia, y el Caribe habían sido repartidos por las naciones europeas, existía una inmensa y lejana región que parecía ser el último espacio disponible para la expansión del sistema imperialista: el continente helado. Fue así que, durante la llamada era heroica, las naciones europeas -Reino Unido, Francia, Bélgica y Noruega, entre otrasdesplegaron importantes esfuerzos para consolidar su presencia en el lejano polo austral, al que consideraban "sin dueño".

Paradójicamente, mientras la decadente Europa aseguraba su lugar en el continente blanco, Estados Unidos -potencia de creciente influencia mundial- permanecía al margen de la carrera por la Antártica. Pese a la singularidad de esta situación, no ha existido mayor interés de parte de la academia por ahondar en este relevante capítulo de la historia polar, dando lugar a un evidente vacío de conocimiento en el desarrollo de la era heroica. Explorar en la inacción antártica de Estados Unidos a comienzos del siglo XX podría colaborar a entender, entre otros aspectos, cómo las naciones europeas pudieron llevar a cabo el "reparto" de la Antártica sin mayor oposición internacional, replicando de manera más o menos similar lo que ya habían realizado en otras regiones del planeta, y dando lugar al entramado conflicto de soberanía que hasta hoy se mantiene en el continente austral.

De acuerdo a lo anterior, el presente trabajo explora las razones de la inacción de Washington en la Antártica, a inicios del siglo pasado, y especialmente, analiza las visiones de la comunidad científica frente a ello. Con tal objetivo, se revisó la totalidad de las publicaciones oficiales (revistas y boletines) de la American Philosophical Society, la American Geographical Society, y la National Geographic Society, entre 1900 y 1912; así como las 
actas, correspondencia y otros documentos oficiales emitidos por dichas instituciones. A lo anterior, se incorporó bibliografía especializada y material de prensa extraído de diarios y periódicos de Estados Unidos, Gran Bretaña y Chile durante el mismo periodo. De este modo, y mediante el uso de estas fuentes, se pretende arrojar algo de luz sobre un aspecto escasamente estudiado de la historia antártica mundial, pero que resulta fundamental para entender el comportamiento de Estados Unidos en el polo austral, así como el complejo devenir del continente durante el siglo XX.

\section{ESTADOS UNIDOS Y LA ERA HEROICA}

Como ha sido profusamente estudiado a través del tiempo, durante la primera década del siglo XX la Antártica fue escenario de una desatada competencia internacional entre las principales potencias de la época y algunas otras naciones con intereses en el región. Afanados tanto en expandir el conocimiento científico sobre el continente blanco, como en marcar presencia en tierras que consideraban "de nadie" o "sin dueño" (terra nullius), el Reino Unido, Francia, Bélgica y Noruega, entre otros, llevaron a cabo ambiciosas expediciones que aspiraban a desentrañar los secretos del rincón más hostil del planeta. Dichas iniciativas configuraron lo que se ha denominado como era heroica de la exploración antártica; periodo histórico que se extendió, aproximadamente, desde los últimos años del siglo XIX hasta el estallido de la primera guerra mundial. Uno de los orígenes de este extraordinario periodo de exploración científica puede hallarse en el Sexto Congreso Geográfico Internacional, realizado en Londres en 1895. En dicha cumbre se resolvió que, por ser la Antártica "una de las regiones más importantes que aún quedaba por explorar", se recomendaba a todas las sociedades científicas del mundo iniciar trabajos allí antes de finalizar el siglo (Reporte Sexto Congreso Geográfico Internacional, 1895, p. 780).

De tal manera, el periodo heroico, cuyo punto más significativo sería la conquista del polo sur geográfico en 1911, se inició con una expedición belga liderada por Adrien de Gerlache, la que se extendió desde 1897 hasta 1899. Le siguieron las expediciones de Carsten Borchgrevink (1898-1900); Erich von Drygalski (1901-1903); Otto Nordenskiold (1901-1903); Robert F. Scott (1901-1904); William S. Bruce (1902-1904); y Jean-Baptiste Charcot (19031905), posicionando de este modo a Bélgica, Alemania, Suecia, el Reino Unido y Francia, en la vanguardia de la exploración antártica. Más adelante se desarrollarían nuevas expediciones que, con mayor o menor éxito, también contribuirían a profundizar el conocimiento sobre la región durante los primeros años del siglo XX.

Mientras las potencias europeas competían por la exploración de un continente lejano, prácticamente desconocido y sin valor económico aparente, Washington concentraba su atención en otras regiones del globo, absteniéndose de organizar misiones hacia las frías latitudes antárticas. Se configuraba, de esta manera, un paradójico escenario, en el que algunos imperios en decadencia -como el británico o el francés- acrecentaban su 
influencia en los mares y tierras australes, mientras una potencia emergente, Estados Unidos, decidía marginarse de la carrera por el continente helado. Para entonces, el país del norte privilegiaba su participación en la exploración de las regiones árticas y en otros proyectos menos románticos, que pudieran ofrecer réditos económicos y ventajas estratégicas en el corto plazo. No es de extrañar entonces que Washington priorizara sus objetivos en los inmensos mercados del lejano oriente, así como en las cercanas regiones del Caribe y América Central. Justamente en Panamá, el país del norte había asumido la titánica tarea de construir un canal interoceánico que sería clave en las comunicaciones y en el comercio marítimo mundial.

Si se considera -como numerosos investigadores sostienen- que fue la actividad ballenera la que reactivó el interés del mundo por el continente helado, puede apreciarse con mayor claridad el porqué de la ausencia de Estados Unidos en la denominada era heroica (Hemmings, Dodds \& Roberts 2017, p. 1). Y es que, como han descrito Johan N. Tonnessen y Arne O. Johnsen (1982), el país del norte no contaba para inicios del siglo XX con una industria ballenera importante, que pudiera participar del creciente negocio de la caza de cetáceos en los mares australes y antárticos (pp. 160-162). Ya desde las últimas décadas del siglo anterior, dicha industria enfrentaba una profunda crisis en el hemisferio norte, dada principalmente por la caída del precio del aceite de cetáceos en los mercados mundiales. Las potencias industriales habían dejado de depender de dicho recurso, reemplazándolo por productos sintéticos o por otros más baratos y fáciles de conseguir (May, 2013, p. 10). Estados Unidos, al inundar el mercado mundial con su masiva producción de aceite vegetal -por ejemplo- había incidido directamente en el declive de la caza de ballenas por parte de compañías europeas (1892-1905), asestando de paso un golpe letal a su propia industria ballenera (Epstein, 2008 p. 36).

Cuando parecía no haber solución para esta crisis internacional, Europa concentró su mirada en las inmensas poblaciones de cetáceos existentes en los mares antárticos. Las dificultades geográficas y climáticas de la región pronto se verían minimizadas con la modernización de los métodos en la caza de ballenas, entre ellos, el desarrollo de arpones explosivos y la construcción de buques-factoría ('Whale-hunting old and new', 1905, p. 4). Lo anterior permitiría a los balleneros británicos, noruegos y suecos -entre otros- cazar a sus presas de manera más eficiente y segura en las desafiantes aguas del polo austral, cuestión que, en el corto plazo, revitalizaría la alicaída industria. Como resultado de aquello, las naciones europeas con intereses en la Antártica ya no sólo aspiraban a incrementar el conocimiento geográfico y científico en la región, sino que vislumbraban la posibilidad cierta de explotar económicamente los recursos del continente blanco y sus mares circundantes. En tal sentido, y de acuerdo a Edward J. Larson -en su obra An Empire of Ice- aunque la exploración de la Antártica durante la era heroica fue fundamentalmente científica, en diseño y ejecución, también involucró motivaciones militares, comerciales, ideológicas y personales (2011, p. ix). Estados 
Unidos, al no expandir su industria ballenera hacia la Antártica, vería limitadas sus posibilidades de participar en cualquier proyecto científico o comercial en el continente. ${ }^{2}$

Consecuentemente, para inicios del siglo XX, las exploraciones realizadas por Nataniel Palmer (1820) y Charles Wilkes (1838-1842) seguían siendo las más significativas incursiones de ciudadanos estadounidenses en aguas antárticas (Balch, 1911, p. 282). Mientras Palmer, afamado capitán ballenero originario de Connecticut, es sindicado como uno de los descubridores de la península antártica, Wilkes es recordado por liderar una expedición de circunnavegación mundial que, en su travesía por los mares australes, habría confirmado la existencia del continente antártico, dando nombre además a una extensa región de éste: Wilkes Land. Hacia comienzos del 1900, dicha región sería foco de una intensa controversia entre exploradores, científicos, y autoridades del país del norte, alcanzando incluso ribetes internacionales (Balch, 1906, p. 30).

Pese a que la expedición comandada por Wilkes -miembro de la marina norteamericanaseguía siendo para entonces la única de carácter oficial realizada por el país del norte en el continente blanco, no había conseguido mayor valoración por parte de la opinión pública, las autoridades, o las fuerzas armadas de los Estados Unidos. Más aún, parte importante de la comunidad académica y científica del país del norte, así como la propia Marina, desconocían lo realizado por Wilkes y, en otros casos, negaban la veracidad y la importancia de los descubrimientos que el navegante había realizado en el extremo austral del planeta. No es de extrañar entonces que, ante la evidente ventaja que las naciones europeas llevaban en el desarrollo de la era heroica, algunas de las más importantes sociedades científicas estadounidenses hayan intentado convencer al gobierno norteamericano de la necesidad de implementar una política más activa en los asuntos del continente antártico.

\section{¿UNA EXPEDICIÓN ANTÁRTICA ESTADOUNIDENSE?}

Las notables expediciones realizadas por europeos durante la era heroica en la Antártica no pasaron desapercibidas para algunas de las más importantes sociedades científicas de los Estados Unidos. Estas instituciones -entre ellas la American Philosophical Society, la American Geographical Society, y la National Geographic Society- observaban con preocupación cómo el país del norte perdía una valiosa oportunidad para incrementar su desarrollo científico y para extender su influencia en una región de insospechada importancia a futuro. De tal manera, y a través de sus publicaciones oficiales, estas instituciones dieron paso a un debate sobre las responsabilidades que Estados Unidos debería asumir en el continente blanco, ello, en consideración a su creciente status de potencia internacional; a la competencia de otras naciones industrializadas; $y$, especialmente, a los aportes que ciudadanos norteamericanos habían realizado a la

2 Para inicios del siglo XX, la industria norteamericana estaba dejando atrás gran parte de los productos derivados de cetáceos, reemplazándolos por otros que pudieran elaborarse con materiales sintéticos o vegetales. Ejemplo de ello fue la elaboración de margarina a partir de aceite vegetal, y la sustitución de huesos y barbas de ballenas por plástico. 
exploración y navegación en la región antártica en el pasado. ${ }^{3}$ En tal sentido, Edwin S. Balch constituyó una de las más destacadas figuras que presionó para conseguir la participación oficial de Estados Unidos en la era heroica del continente blanco.

Abogado, explorador, y miembro de la American Geographical Society -así como de otras instituciones científicas de los Estados Unidos- Balch asumió la compleja tarea de poner en valor lo realizado por ciudadanos estadounidenses en la Antártica, exigiendo al gobierno norteamericano que llevara a cabo una expedición a dicha región durante la primera década del siglo XX. Mediante numerosos artículos publicados en las principales revistas de las sociedades científicas estadounidenses, Balch defendió los descubrimientos realizados por Wilkes durante su expedición. Lo anterior, debido a los constantes cuestionamientos realizados por parte importante de la comunidad científica internacional, así como también por algunos personeros del gobierno de Estados Unidos, e incluso por miembros de la Marina de aquel país.

Fue así como en 1905 Balch denunció, a través del Bulletin de la American Geographical Society, que el destacado geógrafo inglés Sir Clements R. Markham, atacaba constantemente la figura Charles Wilkes, así como la de otros exploradores estadounidenses, negando sus aportes al conocimiento antártico de la época (Balch, 1905, p. 719). La denuncia de Balch no era menor, pues Markham, desde su cargo de presidente de la Royal Geographical Society (Londres), había sido uno de los principales promotores de la exploración antártica internacional a partir de 1890, y una pieza clave en la realización de la Expedición Antártica Británica (19011904) liderada por Robert F. Scott (Larson, 2011, pp. 76-78). ${ }^{4}$ A comienzos del 1906, Balch denunciaría directamente al propio Scott por negar los descubrimientos de Wilkes. De acuerdo a lo señalado por Balch, el capitán Scott había declarado a la prensa londinense que -gracias a sus propias exploraciones en el continente helado- había "descartado definitivamente" la existencia de Wilkes Land, desacreditando así al más importante explorador antártico de los Estados Unidos hasta ese entonces (Balch, 1906, p. 31).

La crítica perspectiva de Balch era compartida por Robert Peary y Frederick Cook, influyentes exploradores polares estadounidenses de comienzos del siglo XX, cuya rivalidad -con el tiempo- los llevaría a enfrentarse en una pública controversia para adjudicarse el título de ser el primero en haber llegado al polo norte. Y es que, a diferencia de lo que ocurría con la Antártica, el extremo boreal del planeta si parecía ejercer una fuerte atracción para Estados Unidos, ya fuere por su cercanía geográfica o por las ventajas económicas y geopolíticas que implicaba el control de la región. Aunque con resultados mayormente desalentadores, el país del norte había incursionado en el Ártico repetidas veces desde las últimas décadas del siglo XIX (Taylor, 1981, 370-376). Algunos de los más connotados expedicionarios estadounidenses

3 Dichas publicaciones fueron: Proceedings of the American Philosophical Society; Bulletin of the American Geographical Society; y The National Geographic Magazine.

4 Por su destacado trabajo como explorador y geógrafo, así como por su influencia en el desarrollo de las expediciones antárticas europeas a partir de la década de 1890, Markham puede ser calificado como uno de los impulsores de la llamada era heroica de la Antártica. 
en dicha región fueron Charles Francis Hall (Expedición Polaris, 1871) y George W. DeLong (Expedición Jeannette, 1879); destacando también el empuje del empresario William Ziegler, quien financió una misión a cargo de Evelyn B. Baldwin (Expedición Baldwin-Ziegler, 1901), y otra liderada por Anthony Fiala (Expedición Polar Ziegler, también conocida como Expedición Fiala, 1903-1905) (Peary, 1905, p. 140). Ernest de Koven Leffingwell, quien fuera parte de la expedición de 1901, también ocupó un lugar de renombre, al liderar la llamada Expedición Polar Anglo-Americana (1906-1908), la que condujo exploraciones en el mar de Beaufort. Robert Peary, el más afamado de los exploradores estadounidenses en el Ártico, había realizado expediciones en Groenlandia desde 1886, y llevó a cabo intentos para alcanzar el polo en 1905, y luego en 1908 ('Commander Peary's Arctic Expedition', 1906, p. 683).

La evidente predilección estadounidense por el polo norte se profundizó aún más cuando el interés de los más importantes exploradores europeos comenzó a orientarse hacia la Antártica ('Expeditions in the Arctic and Antarctic', 1902, p. 179-180). Así lo destaca Edward J. Larson, quien afirma que, a comienzos del siglo XX, los británicos prácticamente habían abandonado la exploración del Ártico para concentrarse en el continente austral, dado que este último representaba un desafío científico mucho mayor, dejando así el polo norte en manos de Estados Unidos (Larson, 2011, p. 13). Esta división de intereses polares entre británicos y estadounidenses, parecía haberse graficado, asimismo, en las palabras que el embajador norteamericano en Londres, Joseph Hodges Choate, enunció en noviembre de 1904. En tal fecha, y durante una exposición realizada por Robert F. Scott en el Royal Albert Hall -al volver de la Antártica- Choate señaló que si el Reino Unido permitía a Scott completar su trabajo [alcanzar el polo sur] y si Estados Unidos daba una oportunidad similar a Robert Peary en el norte, entonces ambas naciones, conquistando cada uno de los polos, "darían al mundo el cálido y fraterno abrazo de la raza anglo-sajona” ("The National Antarctic Expedition', 1904, p. 6). Para entonces, Peary ya afirmaba públicamente -a través de la National Geographic Magazine- que "no existía persona que creyera más en el valor y la necesidad de realizar una exploración al polo sur que él". Lo anterior, pese a la evidente predilección que el explorador tenía por el Ártico (Peary, 1904, p. 391).

En efecto, Robert Peary, quien por entonces ocupaba el cargo de presidente de la American Geographical Society (1903-1907), era consciente de la necesidad de que Estados Unidos se involucrara en la exploración antártica. Mientras diferentes expediciones europeas recorrían dicho continente y sus mares circundantes, y en medio de un generalizado desinterés estadounidense por la región, Peary se mostraba convencido de que las sociedades geográficas del país, así como las instituciones científicas y el gobierno debían actuar mancomunadamente para llevar a cabo una expedición oficial al continente helado (Peary, 1904, p. 391). El explorador creía que si se tomaba ventaja de lo realizado por las expediciones europeas, bastarían sólo "dos barcos bien equipados" para que Estados Unidos conquistara el polo sur. De tal manera -y como afirmó durante su discurso en la reunión anual de la American Geographical Society (enero de 1905), se avanzaría hacia la expansión del 
conocimiento antártico del país del norte, “con una gran cantidad de nuevo y valioso material proveniente de una región prácticamente desconocida” (Peary, 1905, p. 142). Evidentemente, Peary pretendía liderar esta posible expedición, posicionándose como explorador de ambos polos, cuestión ya conseguida, entre otros, por Frederick A. Cook, el más claro rival de Peary en aquel entonces.

Irónicamente, Cook se había iniciado en la exploración polar como parte de una expedición al Ártico comandada por el propio Peary (1891-1892), en la cual había ejercido labores de médico. Realizando una tarea similar, Cook participó también de la expedición belga liderada por Adrien de Gerlache (1897-1899) y que diera inicio a la era heroica en la Antártica. En noviembre de 1904, ya con una importante experiencia acumulada en cuanto a la exploración en ambos extremos del planeta (ventaja de la que no gozaba Peary), Cook -a través de la National Geographic Magazine- hacía hincapié en que el conocimiento que Estados Unidos poseía sobre el continente blanco era "incompleto y limitado", enfatizando que había que incentivar la realización de expediciones nacionales tanto al polo norte como al polo sur (Cook, 1904, p. 461). A pesar de la conocida rivalidad entre ambos, Peary y Cook coincidían en que las potenciales expediciones de Estados Unidos a la Antártica debían ser oficiales; es decir, tenían que contar con la participación directa del gobierno, o más precisamente, de la Marina norteamericana. Sin embargo, y para malestar de ambos, Washington permanecía -a veces incomprensiblemente- reacio a organizar una expedición de este tipo. Aparentemente, el gobierno seguía sin entender la importancia de tal misión, ni tampoco era capaz de advertir la ventaja que otras naciones estaban consiguiendo en materias de exploración y desarrollo científico en la Antártica.

De este modo, y mientras Estados Unidos seguía sin asumir el desafío antártico, el Reino Unido y otras potencias europeas continuaban profundizando su conocimiento sobre el continente austral. Así, por ejemplo, y desde el fin de su exitosa misión en la Antártica (septiembre 1904), Robert F. Scott se había transformado en una figura de influencia internacional, dedicando parte importante de su tiempo -mientras preparaba una nueva misión- a relatar las proezas de la Expedición Discovery (1901-1904) y los avances que los científicos británicos habían conseguido en el continente helado ('Return of the British Antarctic Expedition', 1904, pp. 293-294). El Reino Unido estaba a la vanguardia de la exploración y la ciencia antártica, y aquello, sin lugar a dudas, sería fundamental para que el imperio consolidara, en el corto plazo, su poder en la región mediante reclamaciones territoriales que marcarían el complejo futuro político de la Antártica ('Seizing Antarctic Lands', 1909, p. 6). ${ }^{5}$

Por el contrario, parte importante de los círculos científicos y académicos de Estados Unidos veían como su país, sin una explicación convincente, quedaba relegado del continente

En 1908 el gobierno británico emitiría una carta patente reclamando bajo su soberanía importantes territorios ubicados en los mares australes y el continente antártico, vinculándolos administrativamente a la autoridad de las islas Falkland. Este hecho constituyó el primer reclamo de territorio en el continente helado, y dio paso al entramado conflicto por la soberanía de la región que persiste hasta el día de hoy. 
antártico. Al respecto, Edwin S. Balch se preguntaba a comienzos de 1906: “Será posible incentivar el interés del gobierno de Estados Unidos en materia antártica? ¿No querrá algún multimillonario estadounidense contribuir al estudio del descubrimiento geográfico más grande del siglo XIX?" (1906, p. 32). Refiriéndose a lo realizado por Charles Wilkes en 1840, y al no encontrar respuesta por parte de la autoridad, Balch se inclinaba ahora a aceptar la iniciativa privada, probablemente con la esperanza de encontrar a alguien que pudiera financiar una expedición estadounidense a la Antártica, tal como William Ziegler lo había hecho en el polo norte. No tendría éxito.

\section{LOS ÚLTIMOS INTENTOS}

Balch no era el único que tenía una visión crítica sobre la inacción de Washington en materia antártica. En marzo de 1906, la American Geographical Society, a través de una carta formal enviada por Chandler Robbins a la Marina norteamericana, insistía en la conveniencia de llevar a cabo una expedición oficial a la Antártica, con el objetivo de confirmar los descubrimientos realizados por Charles Wilkes en 1840. De alguna manera, se entendía que la comprobación de los hallazgos de Wilkes podría asegurar a Estados Unidos un lugar de influencia entre las naciones con intereses en la región, especialmente cuando el paso de los años parecía confirmar su valor económico y estratégico.

La respuesta a la misiva de Robbins, fue entregada por Truman H. Newberry, Secretario Asistente de la Marina, quien afirmó que, en ese momento, "no existía ninguna nave de la Armada de Estados Unidos disponible para ser enviada a la Antártica”. Al mismo tiempo, y entregando algunas luces sobre el desinterés oficial por el continente blanco, Newberry argumentaba que era probable que "las tierras montañosas reportadas por Wilkes al este de Adelie Land, no existiesen”, y que la presencia de otras tierras al oeste parecía también ser "poco probable" (Newberry, 1906, p. 4). La decidora declaración de Newberry, que cuestionaba claramente los descubrimientos de Wilkes, parecía echar por tierra cualquier esperanza de que el gobierno de Washington pudiera -en el plazo inmediato y a través de la Marina- involucrarse activamente en la exploración antártica.

Estados Unidos, pese a su creciente influencia internacional y a su destacado nivel industrial y tecnológico había preferido permanecer al margen de la carrera por el polo austral, lo que generaba enérgicas reacciones entre la comunidad científica y académica. Como señalara Edwin S. Balch en los Proceedings de la American Philosophical Society, en abril de 1909, "Estados Unidos no estaba cumpliendo con su parte en la exploración de la Antártica [mientras] otras naciones estaban haciendo el trabajo y llevándose la gloria” (Balch, 1909, p. 37). Y es que Europa continuaba con la organización de nuevas misiones hacia el continente blanco, las que -hacia fines de la primera década del siglo XX- estarían representadas en las expediciones del británico Ernest Shackleton (1907-1909), y del francés Jean-Baptiste Charcot (1908-1910) (Balch, 1911, p. 81). Estas nuevas misiones -particularmente 
la de Shackleton- parecieron reactivar el anhelo de las sociedades científicas norteamericanas de conseguir la organización de una expedición nacional a la Antártica. En tal sentido, en mayo de 1909, Isaac M. Hays, Secretario de la American Philosophical Society, intentó unir fuerzas con otras organizaciones similares, haciendo entrega de una propuesta a su par de la American Geographical Society. En uno de sus párrafos el documento señala:

"La American Philosophical Society ha decidido que, ya que Estados Unidos no ha tomado parte en las recientes exploraciones de las regiones del polo sur, se solicitará la cooperación de las sociedades científicas y geográficas del país, para instar al gobierno a hacer los esfuerzos necesarios para enviar una nave, bajo la dirección de la Marina, a explorar y estudiar las costas de Wilkes Land, y otras partes de la Antártica" (Hays, 1909, p. 1).

Como era de esperar, esta iniciativa no tuvo mayor efecto en el gobierno, por lo que las sociedades científicas continuaron con nuevos esfuerzos. En diciembre de 1909, Archer M. Huntington, por entonces nuevo presidente de la American Geographical Society, envió una carta a George von Lengerke Meyer, Secretario Naval de los Estados Unidos. Con un tono menos amistoso -incluso irónico- Huntington señalaba: “Se puede ahora enviar a una nave para que siga la ruta de Wilkes y verifique si es posible divisar tierra cerca de los lugares donde él reportó su existencia?” El presidente de la entidad científica claramente hacía referencia al argumento dado en 1906 por Truman H. Newberry, cuando señalaba que no existían buques de la Armada de Estados Unidos que estuvieran preparados para una misión a la Antártica. Huntington, finalizaba su misiva a Meyer señalando que "debería ser de interés de la Marina hacer algo para salvaguardar la reputación de Wilkes” (Huntington, 1909, p. 1).

La permanente reticencia del gobierno y de la Armada de Estados Unidos, para realizar una expedición a la Antártica, resultaban incomprensibles para las sociedades científicas, especialmente cuando se recurría a una supuesta precariedad de la flota naval como justificación. Lo anterior, porque el gobierno de Theodore Roosevelt había llevado a cabo -entre diciembre de 1907 y febrero de 1909- una ostentosa circunnavegación mundial mediante la que sería conocida como la "gran flota blanca". Dicha flota se componía de 16 buques acorazados y sus correspondientes naves escoltas que, en un despliegue sin parangón del poder naval de Estados Unidos, había recorrido los principales mares del planeta y visitando numerosos puertos en todos los continentes, por supuesto, a excepción de la Antártica ('El viaje de la escuadra del Pacífico', 1907, p. 2).

$\mathrm{Al}$ acercarse el final de la primera década del siglo XX el continente helado seguía siendo un desafío para la exploración y la ciencia mundial. En tal escenario, la conquista del polo sur geográfico constituía el máximo galardón a obtener, y Estados Unidos todavía podía sumarse a los esfuerzos por conseguirlo. Robert Peary se preparaba entonces para su histórica misión al Ártico, donde reclamaría -no sin generar controversia- haber sido el primer 
hombre en conquistar el polo norte en abril de 1909 ('Discovery of the North Pole', 1909, p. 575). Poco tiempo antes, en diciembre de 1908, Peary afirmaba en la National Geographic Magazine que al regresar del polo boreal "emprendería la organización de una expedición nacional a la Antártica, para asegurar [para Estados Unidos] parte del honor y de la valiosa información científica que todavía quedaba por explorar en la región” ('An American South Polar Expedition, 1908, p. 885). Sin embargo, al volver del Ártico, Peary se encontró con un recibimiento que no esperaba. Su antiguo rival, Frederick Cook, aseguraba haber llegado al polo norte un año antes, cuestionando así lo realizado por Peary (Cook, 2001, pp. 301302). Los expedicionarios se desacreditaron mutuamente, enfrascándose en una disputa que no sólo afectó la reputación de ambos, sino que también pareció limitar aún más las posibilidades de llevar a cabo una expedición a la Antártica por parte de Estados Unidos. ${ }^{6}$

Pese a la compleja situación que vivía, Peary propuso la realización de tal expedición a la National Geographic Society en febrero de 1910, la que esperaba realizar en conjunto con el Peary Arctic Club. ${ }^{7}$ El objetivo sería explorar la costa del mar de Weddel, "y si fuera posible, llegar al Polo Sur a través de esa ruta” ('The South Polar Expedition', 1910, p. 167). Pese a que durante años había respaldado y presionado a las autoridades para conseguir la organización de una expedición estadounidense a la Antártica, el directorio de la National Geographic Society fue reticente a la propuesta de Peary, señalando que sólo la aceptarían "después de consultarlo con los miembros de la sociedad, y siempre y cuando el proyecto tuviera suficiente respaldo financiero para garantizar su emprendimiento". En definitiva, la entidad científica no descartó tajantemente la propuesta de Peary, pero no se comprometió a financiarla. En su respuesta oficial, el directorio de la organización señaló: "Si los recursos de la sociedad fueran mayores, haríamos una apropiada contribución para este proyecto. Todos nuestros fondos, sin embargo, los necesitamos en casa” ('The South Polar Expedition', 1910, p. 169). ${ }^{8}$ Ya no sólo el gobierno de Estados Unidos se mostraba contrario a la realización de un expedición nacional antártica. También al interior de algunas sociedades científicas -ya fuere por agotamiento, por razones económicas, o por desconfianza hacia los controvertidos expedicionarios polares- parecían asomar dudas sobre la conveniencia de tal proyecto.

En marzo de 1910, y aunque seguía permaneciendo ajeno a la exploración antártica, Estados Unidos experimentó una efímera fascinación con el continente helado, cuando Ernest Shackleton visitó el país. Su reciente y exitosa misión en la Antártica lo habían motivado a realizar una serie de conferencias pagadas en Europa y América, mediante las cuales pretendía

6 Aunque ninguno de los exploradores logró demostrar científicamente su hazaña en el polo norte, la academia norteamericana apoyó mayoritariamente la posición de Peary, un resultado que, en buena medida, pudo haberse debido a su influencia como ex presidente de la American Geographical Society. De acuerdo al conocimiento actual, se cree que ni Cook ni Peary alcanzaron el extremo boreal del planeta.

7 El Peary Arctic Club, surgido en 1898, reunía a un importante grupo de colaboradores y patrocinadores que -mediante su apoyo y donaciones- permitieron la realización de diversas expediciones lideradas por Robert Peary, principalmente en territorio de Estados Unidos y en el Ártico. La más importante de ellas fue la expedición de 1908-1909, en la que Peary reclamó haber llegado al polo norte.

8 Curiosamente, al poco tiempo, la National Geographic Society apoyaría con cuantiosos fondos la expedición de Hiram Bingham que concluyó con el descubrimiento de Machu Picchu, en Perú. 
financiar -al menos en parte- una nueva misión al polo austral. Shackleton y su esposa fueron recibidos por el presidente William Taft en la Casa Blanca el 26 de marzo, y dos días después recibió de parte de la American Geographical Society, la Medalla Geográfica Cullum, como reconocimiento a sus logros en el continente helado ('Sir Ernest Shackleton Receives the Cullum Geographical Medal', 1910, p. 241).

El expedicionario británico continuó con su tour en Filadelfia, Boston y Nueva York, donde se reunió con Robert Peary. Sin embargo, y pese a la efervecencia que causó en la opinión pública norteamericana, la presencia de Shackleton en Estados Unidos no pareció suficiente para incentivar la realización de una expedición al continente blanco. El país del norte no contaba por entonces con grupos o individuos al interior del establishment político y militar que fueran sensibles al tema antártico. Una de las pocas figuras influyentes de la política estadounidense que había mostrado cierto interés en los asuntos del polo austral era el flamante senador por New York, y ex-secretario de Estado, Elihu Root (1905-1909), quien había propuesto levantar un monumento en honor a Charles Wilkes. Considerando aquello, Chandler Robbins -de la American Geographical Society- escribió a Root en marzo de 1910, señalando:

“Tengo la esperanza que pueda sumarse al esfuerzo de conseguir que el gobierno de Estados Unidos envíe una nave de la Marina para re-explorar las costas de Wilkes Land [...] La conquista del Polo Sur y las exhibiciones de los museos pueden ser dejados a la empresa privada... Pero la exploración de aquellas costas debería quedar en manos del gobierno" (Robbins, 1910, p. 1).

La respuesta del senador sería clara y prácticamente no dejaría espacio a la discusión:

"Pienso que puede ser muy interesante lo que me propone, pero tengo muchos otros asuntos en mis manos, que demandan todo mi tiempo y atención [...] por ello, me temo que no puedo interceder por usted ante el Departamento de Marina en esta ocasión" (Root, 1910, p. 1).

Al poco tiempo, de este desalentador intercambio epistolar, el noruego Roald Amundsen conquistó el polo sur geográfico, ganando la carrera contra Robert F. Scott, quien -en cambioperdería su vida y la de sus compañeros en su viaje de retorno, dando lugar a uno de los más trágicos capítulos de la era heroica. No obstante, y luego de la proeza de Amundsen, se desarrollarían nuevas y ambiciosas expediciones en la Antártica, lideradas por Nobu Shirase (Japón, 1910-1912); William Filchner (Alemania, 1911-1913); y Douglas Mawson (Australia, 1911-1914). Ninguna de ellas, sin embargo, sería suficiente para acabar con la inacción antártica de los Estados Unidos. Sólo la fugaz visita de Ernest Shackleton al país del norte parecía haber generado algo de interés por el continente helado en el presidente William 
Taft. Fue así que en 1912 el mandatario afirmó que no estaba lejano el día "en que tres banderas de barras y estrellas señalen en tres sitios equidistantes la extensión del territorio de Estados Unidos: una en el polo norte, otra en el canal de Panamá y la tercera en el polo sur" (Bowden, 2009, p. 233). Aunque se desconoce si con esta frase Taft estaba deslizando alguna posible política oficial hacia la Antártica, lo cierto es que cualquier plan en tal sentido se vería abruptamente interrumpido por el estallido de la primera guerra mundial.

\section{CONCLUSIONES}

El periodo heroico de la exploración antártica finalizaba junto con los primeros disparos realizados en los campos de batalla europeos, coincidiendo lastimosamente además, con el inicio de una nueva expedición del Reino Unido en el continente blanco, y que -por las circunstancias descritas- estuvo a punto de no realizarse. Ernest Shackleton, el último de los grandes científicos y aventureros de este periodo, pretendía realizar el primer cruce a pie en el continente, desde el mar de Weddell al mar de Ross. Como es sabido, esta misión -denominada Expedición Imperial Transantártica (1914-1917)- fue un rotundo fracaso, pues el Endurance -nave principal de la misión- quedó atrapada en los hielos del mar de Weddell, debiendo ser rescatada por una expedición chilena al mando de Luis Pardo Villalón en agosto de 1916 (Filippi, 2014, p. 252). La era heroica concluía de este modo, sin la participación de Estados Unidos y dejando el continente helado mayoritariamente en manos de europeos.

Aunque es en extremo complejo determinar con certeza los motivos de la inacción antártica de Estados Unidos a partir de un trabajo exploratorio como éste, pueden -razonablemente- identificarse algunos factores que influyeron en dicha conducta. En tal sentido, la poca experiencia de los navegantes norteamericanos en los mares antárticos parece ser un importante elemento a considerar. Al respecto, cabe hacer hincapié en que el ocaso de la actividad ballenera en el país del norte había impedido su expansión hacia los mares antárticos - dificultando, consecuentemente, la especialización de capitanes y tripulantes en la navegación por los hostiles mares australes. Tampoco la Marina de Estados Unidos tenía mayor experiencia en dicha región. De hecho, el punto más austral que había tocado la denominada Gran Flota Blanca durante su travesía, había sido el estrecho de Magallanes (Punta Arenas). Estados Unidos, asimismo, no poseía puertos cercanos al continente blanco, desde los cuales poder operar libremente y con seguridad. En contrapartida, el Reino Unido había desarrollado una importante experiencia tanto en la caza de ballenas como en la navegación por los mares australes y poseía importantes puntos de apoyo en las cercanías de la Antártica: las islas Falkland, Sudáfrica, Australia y Nueva Zelandia colaboraban, en este sentido, como centro de operaciones para las expediciones británicas hacia el continente austral.

De igual manera, parecía que la región antártica estaba fuera de la mentalidad y de los proyectos de los líderes estadounidenses, quienes probablemente la consideraban como un 
espacio perteneciente a la esfera de influencia del imperio británico. Como se ha indicado, sólo William Taft, y de manera tardía y poco clara, realizó algunas referencias al posible interés que el país tenía en el continente helado. A ello se debe sumar que Robert Peary y Frederick Cook -los principales exploradores polares del país del norte- se encontraban enemistados y públicamente desprestigiados, por lo que era complejo entregarles la responsabilidad de dirigir una expedición nacional al polo sur.

Finalmente, y como consecuencia de los factores antes mencionados, parece más o menos claro que el conocimiento de Estados Unidos sobre la Antártica era, como -como alguna vez lo señalara Frederick Cook- "incompleto y limitado". En efecto, la información extraída de las sociedades científicas del país del norte permite entender cuan escaso era el conocimiento que existía a comienzos del siglo XX sobre el continente austral, ignorándose incluso los descubrimientos o las exploraciones realizadas por la propia Marina estadounidense en el pasado. De allí que sea posible comprender el afán de dichas organizaciones por promover no una expedición financiada por privados -como solía ser el caso en el Ártico- sino una liderada por la Armada, que demostrara que Estados Unidos -como potencia emergente de la épocatenía la capacidad y la voluntad de posicionarse entre las naciones antárticas, asegurando así un lugar en el devenir político del continente helado y en el desarrollo de la ciencia polar austral. Esa voluntad no cristalizaría sino hasta 1928, cuando el almirante Richard E. Byrd iniciaría su primera expedición antártica, poniendo fin a la inacción de Estados Unidos en la región, y que se había extendido prácticamente durante un siglo.

\section{REFERENCIAS}

‘El Viaje de la escuadra del Pacífico’. (1907, 17 diciembre). Diario Ilustrado, Chile.

'Seizing antarctic lands'. (1909, 3 septiembre). The Sun, Estados Unidos.

'The National Antarctic Expedition'. (1904, 8 noviembre). Times, Londres.

'Whale-hunting old and new'. (1905, 22 enero). Sunday Magazine, Estados Unidos.

'Address of President Peary'. (1905). Bulletin of the American Geographical Society, Vol. 37, No. 3, 129-143.

‘An American South Polar Expedition'. (1908). National Geographic Magazine. Vol. XIX, No. $12,885-888$.

‘Commander Peary’s Arctic Expedition’. (1906). Bulletin of the American Geographical Society, Vol. 38, No. 11, 683-686.

'Discovery of the North Pole'. (1909). Bulletin of the American Geographical Society, Vol. 41, No. 9, 575-578.

'Expeditions in the Arctic and Antarctic'. (1902). National Geographic Magazine, Vol XIII, No. $5,179-180$.

'Return of the British Antarctic Expedition'. (1904). Bulletin of the American Geographical Society, Vol. 36, No. 5, 293-295. 
'Shackleton's Farthest South'. (1909). National Geographic Magazine. Vol XX. No. 4, 398-402 'Sir Ernest Shackleton Receives the Cullum Geographical Medal'. (1910). Bulletin of the American Geographical Society, Vol. 42, No. 4, 241-243.

Balch, Edwin Swift. 'American Claims in the Antarctic'. (1903). National Geographic Magazine, Vol XIV, No. 1, 77-78.

Balch, Edwin Swift. 'Antarctic Names'. (1912). Bulletin of the American Geographical Society, Vol. 44, No. 8, 561-581.

Balch, Edwin Swift. 'Antarctic Nomenclature'. (1905). Bulletin of the American Geographical Society, Vol. 37, No. 12, 718-720.

Balch, Edwin Swift. 'Charcot's Antarctic Explorations'. (1911). Bulletin of the American Geographical Society, Vol. 43, No. 2, 81-90.

Balch, Edwin Swift. 'Palmer Land'. (1911). Bulletin of the American Geographical Society, Vol. 43, No. 4, 282-283.

Balch, Edwin Swift. 'Why America should re-explore Wilkes Land'. (1909). Proceedings of the American Philosophical Society, Vol. 48, No. 191, 34-50.

Balch, Edwin Swift. 'Wilkes Land'. (1906). Bulletin of the American Geographical Society, Vol. 38, No. 1, 30-32.

Bowden, B. (2009). The Empire of Civilization. The evolution of an Imperial Idea. Chicago: University of Chicago Press.

Bridgman, Herbert L. 'Peary's progress to the Pole'. (1901). Bulletin of the American Geographical Society, Vol. 33, No. 5, 425-431.

Cook, Frederick A. (2001). My Attainment of the Pole. New York: Polar Publishing Company.

Cook, Frederick A. (1904). 'A Comparative View of the Arctic and Antarctic'. National Geographic Magazine, vol. XV, No. 11, 460-461.

Epstein, Charlotte. (2008). The Power of Words in International Relations. The Birth of a AntiWhaling Discourse. Cambridge, MA.: MIT Press.

Filippi, Alfonso M. (2014). Lecciones de un Rescate. Piloto Pardo y el Salvataje de la Expedición de Shackleton a la Antártica por la Armada de Chile. Valparaíso: Corporación Cultural Arturo Prat Chacón.

Hays, Isaac M., al Secretario de la American Geographical Society, 20 mayo 1909, Philadelphia. Hemmings, Alan D., Klaus Dodds y Peder Roberts. (2017). Handbook on the Politics of Antarctica. Cheltenham, UK; Northampton, US: Edward Elgar Publishing.

Huntington, Archer M. (presidente American Geographical Society) a Meyer, George von Lengerke (Secretario Naval Estados Unidos), 1 diciembre 1909, Nueva York.

Larson, Edward J. (2011). An Empire of Ice. Scott, Shackleton, and the Heroic Age of Antarctic Science. New Heaven, US; London, UK: Yale University Press.

May, C. (2013). 'La caza de ballenas en Chile. De Moby a Quintay'. Revista PAT (54), 9-15. Newberry, Truman H. (Secretario Asistente Marina de Estados Unidos) a Robbins, Chandler (American Geographical Society), 8 marzo 1906, Nueva York. 
Peary, Robert E. ‘Address by Commander Robert E. Peary, U.S.N.'. (1904) National Geographic Magazine, Vol. XV, No. 10, 387-392.

Peary, Robert. 'Address of President Peary'. (1905). Bulletin of the American Geographical Society, Vol. 37, No. 3, 129-143.

Report of the Sixth International Geographical Congress. (1895). London.

Robbins, Chandler (American Geographical Society) a Root, Elihu (Senador por Nueva York), 30 marzo 1910, Nueva York.

Root, Elihu (Senador por Nueva York) a Robbin, Chandler (American Geographical Society), 1 abril 1910, Washington DC.

Scott, S. V. (2017). Three Waves of Antarctic Imperialism. En K. Dodds et al (Eds.), Handbook on the Politics of Antarctica (pp. 37-49). Cheltenham, UK: Norhampton, MA.: Edward Elgar Publishing.

Shackleton, E. (1909). The Heart of the Antarctic. National Geographic Magazine, XX, 9721007.

Taylor, C.J. (1981). First International Polar Year, 1882-1883. Arctic, 34(4), 370-376.

Tonnessen, J. N., \& Johnsen, A. O. (1982). The History of Modern Whaling. Berkeley: Los Angeles: University of California Press. 